\title{
ALGUNOS DATOS SOBRE JOSÉ BERMÚDEZ DE CASTRO Y UN PRIMER ACERCAMIENTO A SUS COLABORACIONES EN LA REVISTA ESPAÑOLA (1836)
}

\author{
María José Alonso SeOANe \\ Universidad Complutense de Madrid
}

Apreciado en su época, José Bermúdez de Castro y Díez es actualmente casi desconocido, oscurecido en el campo literario por la fama de su hermano Salvador y, en ocasiones, confundido con él'. Tampoco tuvo la dedicación política, de su otro hermano, Manuel. Hasta ahora, el conocimiento que se tenía de él se limitaba prácticamente a su aplicación al campo de la literatura, en especial, las colaboraciones publicadas en El Artista; colaboraciones que Eugenio de Ochoa incluye en sus Apuntes para una biblioteca de escritores españoles en prosa y verso (París, 1840) y reproduce posteriormente en el Album Pintoresco Universal (Barcelona, 1842-1843). El mismo Ochoa tendrá para él un recuerdo emocionado en su Miscelánea de literatura, viajes y novelas (Madrid, 1867) al evocar a los que fueron amigos entrañables en su juventud:

¡Cuántos dolorosos recuerdos evoca para mí el nombre del conde de CampoAlange! Cuántas nobles sombras de amigos comunes acompañan a la suya en mi Necrópolis! Alli vislumbro [...] la de un excelente poeta, Bermúdez de Castro (D. José), asiduo redactor del Artista, y a cuya composición titulada el Dia de difintos igualan pocas en castellano (Ochoa 1867, págs. 274-275).

Sin embargo, la permanencia dispersa de su obra en periódicos de la época ha llevado al olvido una figura digna de rescate en algunos aspectos de su obra

${ }^{1}$ También con la obra de otro de sus hermanos, Jacobo, que publicó varios libros en París. 
como creador y crítico. A la espera de un estudio posterior que recoja con mayor extensión los distintos aspectos, el objeto de este trabajo se centra fundamentalmente en adelantar algunos datos desconocidos sobre este escritor, especialmente en relación a sus colaboraciones en La Revista Española entre febrero y agosto de 1836 y una visión general de las mismas.

José Bermúdez de Castro y Díez, como consta en su partida de bautismo², nació en Cádiz el $1^{\circ}$ de diciembre de 1807 , siendo bautizado al día siguiente en la parroquia de Nuestra Señora del Rosario. Murió en Jerez, donde vivía con su madre ${ }^{3}$, viuda desde $1823^{4}$, el 17 de julio de $1854^{5}$. Publicó su obra literaria -poesía, relatos, diversos artículos- fundamentalmente en la prensa de la época, especialmente en El Artista, La Revista Española en los años 1835 y 1836; después, ocasionalmente, en otras publicaciones como la Revista Andaluza, la Revista Gaditana y La Alhambra, de Granada.

A la obra publicada hay que añadir algunos manuscritos inéditos: dentro de la documentación familiar depositada en la Real Academia de la Historia, existe un legajo (RAH 9/6993) que contiene papeles que, hasta ahora, no han sido reconocidos como de José Bermúdez de Castro y que con toda seguridad se pueden identificar como pertenecientes a este escritor, la mayoría originales suyos. En el fondo se hallan, además del manuscrito de una novela inacabada, el de varios poemas, entre ellos el original de «Al Gave», publicado precisamente en La Revista Española el 3 de abril de 1836 . También se encuentra, entre otros papeles varios, el manuscrito del poema de Julián Romea «Torre de Tavira», con esta dedicatoria al fin:

2 Libro de Bautismos de la Parroquia de Nuestra Señora del Rosario, de Cádiz (Libro $n^{\circ} 03$, Folio $134 \mathrm{v}^{\circ}$ ). Agradezco la amabilidad con que se me atendió en las búsquedas, que resultaron infructuosas, realizadas con anterioridad en torno a José Bermúdez de Castro en el Archivo Histórico del Obispado de Jerez de la Frontera.

${ }^{3}$ Cfr. Archivo Municipal de Jerez de la Frontera: Padrón vecinal de 1854 y anteriores. Agradezco a D. Cristóbal Orellana González, Jefe de Departamento del Archivo Municipal, las atenciones con que facilitó mi trabajo en el Archivo para este y otros documentos que citaré a continuación.

${ }^{4}$ Cfr. la documentación depositada en la Real Academia de la Historia, Colección Marqués de Lema, leg. 9/6992. Calvo Sanz (1974) cita esta Colección aunque no hace referencia a estos aspectos. Por otra parte, en su obra, centrada en la figura de Salvador Bermúdez de Castro, solamente se encuentra algún comentario ocasional sobre José Bermúdez de Castro; en concreto, acerca del posible influjo que su poesía pudo ejercer sobre la de su hermano menor, así como sobre la posible ayuda que pudo prestarle en la publicación de su primer poema en El Artista (Calvo Sanz 1974, págs. 17 y 105).

${ }^{5}$ Cfr. Archivo Municipal de Jerez de la Frontera: Parroquia de San Miguel, Folio 70 v.; Libro 36 de Defunciones 1853 a 1857, p. 136; Registro Civil, Difuntos, Año de 1854: Jerez de la Fia, 17 de Julio $1854, \mathrm{n}^{\circ} 30$. 
A su querido Pepe Bermúdez

Julián Romea [rubricado]

Madrid 17 de Enero de $1851^{6}$

A pesar de su carácter fragmentario o circunstancial, en los varios textos que se encuentran en el legajo puede observarse la inquietud profunda de José Bermúdez de Castro, su cultura y viajes (estancias en Inglaterra y Francia), su auténtico romanticismo personal, así como su interés por la literatura y el arte en concordancia con él. Todo lo cual se confirma en los textos publicados, especialmente en su poesía lírica, de gran calidad; no tanto, quizá, las más famosas publicadas en El Artista ${ }^{7}$-en especial, «El día de difuntos»- sino, en mi opinión, otras menos conocidas como «Una estrella misteriosa», publicada en El Artista, «Al Gave» (fechada en el original manuscrito en Saint-Saveur, el 25 de julio de 1835), publicada en La Revista Española, y los «Romances» publicados en La Alhambra en $1842^{8}$.

Comparte, con los otros jóvenes de El Artista, un rasgo relevante que da la clave de su postura poco comprendida en España: la estancia en el extranjero en los años de formación y en circunstancias históricas de profundos cambios. José Bermúdez de Castro, un tanto mayor en edad, por su valía creadora y sus conocimientos debió tener entre ellos una voz reconocida y autorizada.

José Bermúdez de Castro coincidió en Madrid con Eugenio de Ochoa y los otros jóvenes que llevarían a cabo la publicación de El Artista, así como con otros escritores y otras personalidades, al menos en las tertulias de la casa de José de Madrazo (Madrazo 1882, pág. 109). Sin embargo, cuando a comienzos de 1835 El Artista llega por fin a ver la luz, José Bermúdez de Castro vive en Jerez, con su madre, atendiendo los asuntos del negocio familiar. Desde allí colabora con la revista ${ }^{9}$ mientras participa en la vida cultural de Jerez, donde el 5 de marzo de

' El poema aparece fechado en Cádiz, 1846. La dedicatoria es del ms. y no aparece en la edición impresa de las poesías de Romea (1861). Actualizo ortografía y puntuación en los textos de época. La fecha entre paréntesis indica la de la publicación en el periódico de la colaboración de José Bermúdez de Castro a la que corresponde la cita o referencia.

${ }^{7}$ Entre los testimonios de época, además de la elogiosa mención de Ochoa, ya citada (1867, pág. 275), hay una referencia curiosa en el epistolario de Domingo del Monte, en que Juan Padrines, al comentar la devolución de algunos ejemplares prestados de El_Artista, escribe, desde Matanzas, el 18 agosto 1836: «Leí con mucho gusto la composición de Bermúdez de Castro sobre los Difuntos y la juzgué digna de quedarme una copia. Matamoros habrá entregado a Vd. los tres números del Artista que se sirvió enviarnos a Miłanés y a mí» (Del Monte y Aponte 1923, t. III, pág. 44).

${ }^{8}$ La Alhambra, 1842, págs. 204-210. A las poesías reseñadas por Rokiski (1988, t. II, s. v.), cabe añadir la publicada en francés en La lira andaluza (II, 1838); por otra parte, se ha deslizado un error con respecto a las que se citan como publicadas por José Bermúdez de Castro en El Piloto ( $« \mathrm{~A}$ Elvira», «La Cenobita» $y$ «La muerte») y que pertenecen a su hermano Salvador.

${ }^{9}$ Su primera colaboración fue el relato breve Los dos artistas, publicado el 14 de junio de 1835 
1835 aparece en las Actas de la Real Sociedad Económica de Amigos del País ${ }^{10}$. A1 parecer, José Bermúdez de Castro está asentado en la ciudad de modo estable cuando, de manera inesperada, a comienzos de 1836 se le presenta la oportunidad de trasladarse a Madrid para incorporarse a la redacción de La_Revista Española". Por las Actas se ve claramente que a finales de año tenía idea de permanecer en Jerez, ya que pasa a ser Secretario de la Real Sociedad para el nuevo trienio, 1836-1839, firmando como tal el 31 de diciembre de 1835. Asimismo aparece su firma en varios documentos correspondientes al traspaso de cargos; en concreto, distintos inventarios que firma con el secretario saliente, José Antonio de Lavalle, el $1^{\circ}$ de enero de $1836^{12}$, casi en el momento en que debe dejarlo porque se va a Madrid. El acontecimiento, de evidente trascendencia para Bermúdez de Castro, queda reflejado en el Acta del 14 de enero de $1836^{13}$ :

En este estado el socio Secretario dijo le era en extremo sensible tener que manifestar a la Sociedad que asuntos personales del mayor interés le obligaban a partir para Madrid en donde todavía no podía puntualizar cuanto scría su detención, que sin embargo esperaba no fuese mucha; y que a haber previsto este incidente no hubiera admitido su cargo, más que se lisongeaba no sería su falta conocida mediante los buenos oficios y aptitudes del socio Vice-secretario. La Sociedad manifestó también mucho sentimiento por tan inesperada partida y expresó los mejores deseos a favor de su socio Secretario, el cual agradeciendolo partió dejando su lugar ocupado por el Sr. Ramos ${ }^{14}$

La ilusión que debió sentir José Bermúdez de Castro al presentársele la ocasión de volver a Madrid para dedicarse a tareas literarias en la redacción de un importante periódico es evidente en estas líneas del Acta, así como la presentación repentina de esta oportunidad. Después de volver de su viaje por Europa,

${ }^{10}$ Sin otros pormenores -ya que se trata de una breve publicación en que se editan, después de la introducción, los Estatutos Fundacionales-, Ruiz Lagos (1972) da su nombre ( José Bermúder»). tal como aparece) en la lista de socios. Pero hay más noticias en las Actas conservadas en el Archivo Histórico Municipal de Jerez de la Frontera, cuyo examen ha resultado muy útil para este estudio.

"Con anterioridad, en La Revista Española se había publicado, resumido en parte. su relato «Los dos artistas» el 28 de junio de 1835, dos semanas después de haber aparecido por primera vez en El Artista, el 14 de junio de 1835. Con respecto a su papel en este periódico en 1836, es posible que sus tareas abarcaran más que la redacción de las colaboraciones que publica en el Folletín pero, al menos de momento, la falta de firma impide su reconocimiento.

12 Expedientes de la Real Sociedad Económica de Amigos del País [RSEAP], E 688, E 689 y E 690 .

${ }^{13}$ El escritor no vuelve a aparecer en las Actas hasta que, en 1841, se da cuenta de lá separación de la Sociedad, que pasa por una gran crisis, de varios socios residentes; entre ellos. José Bermúde\% de Castro y su hermano Manuel (RSEAP, E. 694).

${ }^{14}$ Se trata de Juan Ramos, que firma el Acta y le sustituye en los años sucesivos, hasta el 31 de diciembre de 1839 en que cesa, entregando el cargo al siguiente secretario, Francisco de Paula Barea (RSEAP, E 691). 
Larra había pasado a escribir en el recién fundado El Español y alguien que le conoce y aprecia -quizá Ochoa, o el mismo Larra- habría sugerido a Carnerero la posibilidad de que Bermúdez de Castro fortaleciera la parte literaria de La Revista Española, especialmente en lo que se refiere a la crítica teatral, aunque no exclusivamente. La cuestión es que, en efecto, el escritor se traslada de Jerez a Madrid e inicia sus colaboraciones en La Revista a comienzos de febrero de 1836.

Las colaboraciones de José Bermúdez de Castro se prolongarán a lo largo de los meses, siendo la última el 4 de agosto de 1836, poco antes de la desaparición de La_Revista Española el viernes 26 de agosto ${ }^{15}$, en que pasará a unirse a El Nacional, convirtiéndose junto con este periódico en La Revista Nacional. Las colaboraciones se suceden con cierta irregularidad de frecuencia, en general, en orden creciente hasta junio y decreciente después: dos en total en el mes de febrero (los días 8 y 15), cinco en marzo $(3,9,15,20,26)$, cuatro en abril $(3,7,12$, $30)$, cinco en mayo $(13,20,21,24,27)$, seis en junio $(3,10,16,20,21,24)$, dos en julio $(8,26)$ y la última el 4 de agosto. En total, se publicaron 25 colaboraciones firmadas ${ }^{16}$; las que tienen carácter plenamente creativo con el nombre completo, «José Bermúdez de Castro» - «Los dos artistas» y «Al Gave»-y, las demás - críticas teatrales y reseñas de libros- con las iniciales $«$ J. B. C. $\rangle^{17}$.

El 8 de febrero de 1836, José Bermúdez de Castro inicia su labor en la redacción de La Revista Española, con gran dominio y seguridad, ocupándose de la ópera de Rossini, la Cenerentola; con una reseña en la que demuestra sus conocimientos musicales. El día anterior, domingo 7 de febrero, había publicado en El Artista la primera parte de la «Historia de la muy noble e sublimada seora Leonor Garavito» ${ }^{18}$ y una crítica de la primera representación de Teresa, drama

${ }^{15}$ Como se avisaba en nota, no se pudo tirar el $n^{\circ} 27$ correspondiente al día siguiente, en la crisis sucesiva a la sargentada de La Granja. La Revista Española se había unido previamente, el $1^{\circ}$ de marzo de 1836 a El Mensajero de las Cortes pero La Revista-Mensajero presentaba una continuidad e identidad con su estado anterior que no se dio a partir de su unión con El Nacional.

${ }^{16}$ No se cuenta en este caso la publicación, el año anterior, de la versión de «Los dos artistas». La lista coincide con las colaboraciones incluidas en el Índice publicado por S. Gamazo Berrueco $(1989$, s. v.). Para facilitar una visión de conjunto, incluyo al final del artículo una relación de las mismas, anotando el encabezamiento que aparece en los folletines de La Revista Española. Aunque no forma parte de la serie que estudiamos aquí, anoto también la publicación de «Los dos artistas».

${ }^{17}$ Es posible que pertenezca a él algún tex to no firmado; por ejemplo o en cóncreto, el suelto que aparece inmediatamente después de sus iniciales, en la segunda «Revista de publicaciones nuevas» (3-6-1836), bajo el título de «Novedades teatrales». Aunque menos probable, quizá, la reseña sobre la sesión del Ateneo Científico y Literario en la que Alberto Lista comenzó sus lecciones, que aparece inmediatamente antepuesta a la reseña crítica de Bermúdez de Castro correspondiente al estreno de la comedia ;Está loca! (16-6-1836).

${ }^{18}$ Como es sabido, escrita en -defectuosa- fabla, y con letra gótica en su comienzo, imitando la distribución y los tipos de los antiguos códices. La segunda parte se publicó en lá entrega siguiente (14-2-1836). 
de Alejandro Dumas traducido por Ventura de la Vega ${ }^{19}$; algo excepcional en sus colaboraciones en El_Artista que son de carácter creativo. A partir del 8 de febrero y hasta que termine su trabajo en La Revista Española, Bermúdez de Castro aparece completamente centrado en esta tarea, atento sobre todo a las representaciones teatrales que le corresponde reseñar.

En ocasiones contadas las colaboraciones tienen carácter creativo: «Un baile de estos días» (15-2-1836), narración breve a mitad de camino entre artículo literario y cuento, y la poesía «Al Gave» (3-4-1836), a la que hemos hecho referencia; un texto de gran calidad, porque José Bermúdez de Castro era efectivamente excelente poeta (Ochoa 1867, pág. 275). Su última colaboración, «Esperanzas literarias» (4-8-1836), es un artículo inspirado en una noticia de tribunales de París, sobre las dificultades de los escritores jóvenes, tema recurrente en la literatura francesa del momento, que señala una realidad actual reflejada en los periódicos. Bermúdez de Castro, que comparte con su generación la preocupación por la mala situación profesional del escritor, se muestra especialmente sensible a la falta de protección al autor en España en comparación con Francia; tema al que dedicará un espacio considerable al hablar de la representación de El Trovador a beneficio de García Gutiérrez (15-3-1836).

A finales de mayo, Bermúdez de Castro inicia una nueva sección de crítica de libros que ocuparía algunos folletines y que era, como las reseñas de teatro y la creación, habitual en los periódicos del momento: «Revista de publicaciones nuevas»). Solamente se publicaron tres en total ( 21 de mayo y 3 y 20 de junio de 1836), con una selección de libros no relacionados con la literatura de creación. Desde nuestro punto de vista, tiene mayor interés la primera entrega, dedicada a la obra de Larra La España desde Fernando VII hasta Mendizábal, y al folleto de Espronceda, El ministerio Mendizábal. A propósito de esta obra, Bermúdez de Castro, que se muestra en varias colaboraciones contrario a la censura, afirma haber visto el original completo, diferente de lo publicado:

Difícil sería citar fragmentos que destruirían la necesaria brevedad de este artículo; el que esto escribe ha visto los excelentes trozos que ha amputado la censura, y prueba suficiente del mérito de la obra es el interés que presenta, aún después de haber sido cruelmente mutilada (21-5-1836).

En la segunda «Revista de publicaciones nuevas» (3-6-1836), Bermúdez de Castro reseña el Manifiesto por el Excmo. Sr. D. Pedro María Pastors, mariscal de campo...; en la tercera (20-6-1836), se ocupa de dos obras: Resumen analitico

${ }^{19}$ Algo excepcional en sus colaboraciones en El Artista que son de carácter creativo (los poemas «El peregrino», «Una estrella misteriosa» $\mathrm{y}$ «El día de difuntos»; y las narraciones «Los dos artistas», «Alucinación!!!», además de la citada «Historia de la muy noble e sublimada seora Leonor Garavito»). 
del sistema del doctor Gall y Observaciones acerca de los proyectos de venta o distribución de bienes nacionales (por don Felipe de Pasca y Chávarri).

Bermúdez de Castro excusa el desfase entre la novedad de estas publicaciones y su recogida en la crítica, debido a la necesidad de ceder espacio a otras cuestiones urgentes, como explica varias veces en esta sección (a fin de cuentas, llamada de publicaciones nuevas):

Estas son las últimas publicaciones que queríamos hacer conocer a nuestros suscritores; otro tanto haremos en adelante siempre que nos lo permita la revista de todos los días, porque la literatura espera con modestia, no tiene interregno no se disuelven sus reuniones ni se la llama al orden, por más que salga de la cuestión; solo teme y tiene por implacable enemigo, las afiladas tijeras de la censura, y esa esperamos que cese pronto su odioso ministerio y deje seguir a las artes su libre marcha siempre constante y recta hacia la perfección (20-6-1836) ${ }^{20}$.

El trabajo fundamental de José Bermúdez de Castro en La Revista Española es, sin duda, la crítica teatral, a la que dedica 17 de las 25 colaboraciones de la serie, y en las que despliega su opinión crítica y sus conocimientos de manera que la gran mayoría de las colaboraciones son mucho más que una simple reseña. En aquellas ocasiones en que la obra no merece la pena o de la que, por algún motivo, se ha hablado anteriormente, como ocurre con El trovador, reseñado con motivo de su estreno (3-3-1836) y poco después, por haberse representado a beneficio de su autor (15-3-1836). En estos casos, Bermúdez de Castro las utiliza en parte como pretexto, aprovechando espacio para desarrollar sus ideas literarias que obviamente coinciden, en líneas generales, con las que manifiesta el núcleo esencial de los redactores de El Artista [al que, al fin y al cabo, pertenece] puesto que de él forma parte. Como los responsables de esta publicación, Bermúdez de Castro concibe su trabajo como parte de la ofensiva total que debería conseguir la plena introducción de la moderna teoría literaria del Romanticismo en España ${ }^{21}$.

${ }^{20}$ De modo parecido se había expresado ya en la primera entrega de la sección: «Bueno es confesar antes que el público nos lo advierta, que las publicaciones que siguen no son todas de el día; pero no habiendo dado cuenta en el tiempo que se publicaron, porque otros acaecimientos más importantes, de interés general y de colosales resultados nos llamaban la atención con preferencia, hanos sido preciso hacerlo ahora a pesar del que a transcurrido y de haber pasado la curiosidad primera» $(21-5-1836)$.

${ }^{21}$ Curiosamente, siendo su última colaboración del 4 de agosto, parece que toma el relevo Eugenio de Ochoa -que solo había publicado en La Revista un poema en honor de Federico de Madrazo (9-3-1835) titulado «Elogio del pintor»-, poco antes de que La_Revista Española desaparezca, con la reseña en el Folletín de la noche del 13 de agosto en el teatro del Príncipe, «Beneficio del señor Lombía. Los jesuitas en la corte de Luis XV y el conde de San Germán.- Un pas de deux.- ¡No era ella!» (14-8-1836). Fue, sin embargo, algo excepcional pues Ochoa ya no vuelve a colaborar, probablemente por desacuerdo con el giro político de la publicación. 
En su tarea de crítico que informa al público del periódico de algunas de las representaciones teatrales que están teniendo lugar en los teatros de Madrid, su itinerario sigue necesariamente las incidencias de la actualidad. Entre las obras que le corresponde comentar, de muy distinta entidad, se encuentran varias, como las ya citadas, de autores españoles, siendo la mayoría, traducidas. Las reseñas de José Bermúdez de Castro se dan en el contexto de otras críticas que a la vez iban apareciendo en los demás periódicos madrileños frente a las que se manifiesta completa independencia.

Las críticas tienen por objeto fundamental las funciones ejecutadas en del Teatro del Príncipe, siendo excepcional algunas del teatro de la Cruz. La mayoría se dedican necesariamente a traducciones, aunque no deja de tratarse el que, visto con perspectiva, sería el estreno de la temporada del drama romántico español, $E l$ trovador, de García Gutiérrez, que es convenientemente alabado; y algunas otras obras de distinto carácter, como Aben-Humeya, de Martínez de la Rosa, Elvira de Albornoz, de Díaz, o La redacción de un periódico, de Bretón, de la que señala lo limitado de la comedia cuando tantas posibilidades le ofrecía la profesión de periodista con la que se identifica. Desde otro punto de vista, se muestra muy frío con la tragedia de Fernando Corradi Don_Garcia o el triunfo del amor filial (21-6-1836). Bermúdez de Castro trata muy respetuosamente a Martínez de la Rosa, haciendo alusión a circunstancias que empeoraron los posibles defectos del drama, como el excesivo calor y algunas inverosimilitudes de la puesta en escena, señalando la gran asistencia de público que, en definitiva aplaudió la obra.

Entre las traducciones de obras dramáticas reseñadas hay varias obras importantes, algunas de las cuales dejaron huella en Madrid, y que dan una ocasión especial a José Bermúdez de Castro para exponer sus ideas sobre el moderno teatro francés cuyas representaciones conoce de primera mano; como en el caso de Luis XI, de Delavigne, o Catalina Howard y Antony, de Dumas. En otro orden de cosas, el crítico tiene palabras elogiosas para Scribe, sabiendo diferenciar sus obras mejores y las más ligeras y numerosas. En distintas ocasiones muestra su admiración por Delavigne, en difícil posición entre la ya antigua tragedia y la adaptación a las nuevas tendencias -aunque Bermúdez de Castro diferencia claramente su obra de la línea que representa el Romanticismo ; con respecto a Luis $X I$, atribuye su fracaso en Madrid a la mala traducción y puesta en escena:

Y lo que prueba más que nada el grande ingenio literario de Casimiro Delavigne, es la superioridad de sus dramas, a pesar de esa lucha de impulso y resistencia.

Un día quiso componer una tragedia que entrase en el sistema de literatura moderna, pero como él lo entendía, sin salir de las formas clásicas: dobles grillos con que quiso aprisionarse el poeta. No sabemos con cuantas dificultades, que es imposible comprender, habrá tenido que luchar para seguir la estrecha 
senda, de separación que se había propuesto; una línea que, inclinándose más a un lado que a otro, salía o entraba en uno de esos mismos sistemas. La obra que nació fue del mayor mérito: clásicos y románticos se la apropiaron para su escuela; el entusiasmo que produjo fue general y el número de representaciones excesivo.

Y todo lo merecía, con perdón sea dicho de los que la silbaron noches pasadas, y que no vieron la obra, sino una mala traducción y una pésima ejecución de la obra de Delavigne (12-4-1836).

No podemos detenernos en el comentario a las reseñas de los dramas de Dumas, que necesitan mayor detenimiento y que, muy relacionadas con las ideas literarias de José Bermúdez de Castro, serán objeto de un próximo trabajo; solamente anotar que el crítico hace en cada caso un estudio a fondo del tema y defiende claramente a Dumas -el único de modo pleno en la prensa de Madrid-, no sólo por las bellezas que se encuentran en sus obras sino porque, en definitiva, considera que sus dramas son una muestra de realismo romántico al trasladar desnudamente al arte lo que existe en la sociedad.

La reseñas críticas abarcan todos los aspectos de las representaciones teatrales: calidad del texto, consideraciones generales sobre teoría literaria, traducción, actores y demás elementos de la puesta en escena, así como las reacciones del público; aspectos todos que deben interesar al crítico y que interesan al público lector-en concreto, los suscriptores-del periódico. Bermúdez de Castro se muestra muy consciente de su función como crítico que le lleva a insistir en la honradez en la exposición de sus opiniones, a la vez que predomina en él una actitud crítica de generosidad, comprensión y admiración por los autores que se atreven con las dificultades de la creación literaria; sin dejar por ello de rechazar alguna de las obras que critica, como Los carlistas en la venta, o el cambio de carteras (20-51836), de nulo valor dramático, a la que censura muy seriamente por su detestable zafiedad; sin caer en una posible benevolencia por su temática favorable al liberalismo, como claramente expresa. Por lo general, su actitud empática, de raíz puramente romántica, se manifiesta especialmente con los autores noveles como Díaz, en Elvira de Albornoz -que, por otra parte, encontró la misma actitud de comprensión en la generalidad de la crítica publicada en prensa-, y con El trovador, de García Gutiérrez, en cuya primera reseña expone, precisamente, algunas de sus ideas sobre la actitud del crítico ante la obra que debe examinar:

No reconocemos nosotros en persona alguna, y esto lo hemos dicho ya en otra ocasión, el derecho de inquirir del poeta las razones que le han movido a colocar la escena en tal lugar más bien que en otro, en tal época más bien que en otra, y en pintar tales pasiones, tales personajes, tales caracteres, más bien que otros. El único derecho del crítico, es colocarse a la altura del autor, y después de entrar en sus ideas, de prestarse si puede a todos los vuelos y recortes de su imaginación rápida y voladora, a todas sus sensaciones exageradas de artista, 
a todas las ardientes pasiones de un alma de poeta, juzgar la obra con imparcialidad y decir si es buena o mala; rara vez esta impresión miente o engaña, y el juicio de una exclamacion casi involuntaria al acabar una representación, es más imparcial, más cierta, que el juicio que resulta de un pensado análisis. $\mathrm{Y}$ estas exclamaciones de un público numeroso ¡cuán favorables han sido al autor de El Trovador! (3-3-1836)

Otra materia que, en su conjunto, excede los límites de este artículo es todo lo referente a los actores y a todo lo relativo a la puesta en escena, aspectos que, salvo excepción, nunca se omiten en las críticas. Con respecto a los actores, los beneficios suponen la ocasión de centrar el contenido de las reseñas en la figura de los mismos, más que en las obras representadas en la función correspondiente, como es el caso del beneficio de Bárbara Lamadrid (9-3-1836) o el de Matilde Díaz (26-3-1836). Suelen aparecer comentarios favorables de los actores favoritos del grupo romántico, entre ellos, Julián Romea, Concepción Rodríguez o Matilde Díaz; también se destaca el valer y la popularidad de Guzmán, que salvará siempre cualquier obra, como comenta el crítico a propósito de El hijo en cuestión (24-5-1836). Según la ocasión, Bermúdez de Castro se extiende en la consideración de las cualidades de los actores, siendo en otras breve como en el elogio que hace de la actuación de Bárbara Lamadrid en el estreno de El Trovador: «No olvidaremos tampoco a la señora Lamadrid que ha creado con el autor el papel de Azucena» (3-3-1836).

Las observaciones sobre el decorado y las actitudes de los actores muestran el deseo de dignificar la realidad teatral, y dar a conocer las costumbres que realmente se dan, en España y en el extranjero, especialmente en la alta sociedad, de manera que el comportamiento de los actores tenga verdadero mérito ${ }^{22}$. En ocasiones, la captación apropiada de las costumbres tiene que ver con lo adecuado de la traducción, al referirse a la de Un procurador o la intriga honrada:

La traducción no es mala a pesar de algunas repeticiones, pero creemos que el traductor hubiese hecho mejor en no arreglarla a nuestro teatro. Los procuradores en España tienen costumbres muy distintas de los avoués de Francia, así como un notaire de París no podrá nunca compararse ni por las consideraciones de que goza, ni por los negocios que le ocupan, ni por sus costumbres, con nuestros escribanos. Pero aun en el caso de querer poner a un procurador en la escena dejándolo en francés, y queriendo hacerlo español, debía cuidar que nada recordase que aquello había pasado fuera de España. Cuando se dice allí que a uno le llamaban por su avaricia el Arpagon de Jaén, se le ocurre al más

${ }^{22}$ Entre otras sugerencias, manifiesta en la reseña de ¡Está local: «¿Cómo creer un elegante de Regent-Street tan excesivamente tímido que no se explicase con el tutor de su amante?» (16-61836). 
lerdo que nunca semejante mote puede ser popular en país donde ni lo son, ni pueden serlo, las comedias de Moliére (13-5-1836).

Al terminar José Bermúdez de Castro su participación en La Revista Española en agosto de 1836, tan inesperadamente como la comenzó seis meses antes, dejaba un corpus considerable de colaboraciones en las que demuestra su valía como escritor y crítico; con la actitud generosa que vemos en otros de su generación, que le mueve a promover la introducción completa de un Romanticismo profundo y actual, así como la de esforzarse en colaborar en la tarea de dignificar el teatro español de entonces; tareas todas ellas cuya repercusión resulta dificil de medir actualmente, pero que debió ser digna de consideración en el momento. Su trabajo continúa, en cierto modo, la acción de El Artista cuya desaparición se produce a finales de marzo fundamentalmente por la misma situación que, a los pocos meses y después de una importante trayectoria en la época, se llevó consigo $L a$ Revista Española. 


\section{COLABORACIONES DE JOSÉ BERMÚDEZ DE CASTRO EN $L A$ REVISTA ESPAÑOLA}

1.- «Los dos artistas» (28-6-1835).

2.- «Teatro del Príncipe. Primera representación de La Cenerentola, ópera bufa del maestro Rosini» (8-2-1836).

3.- «Un baile de estos días» (15-2-1836).

4.- «Teatros. Primera representación de El Trovador, drama caballeresco en cinco jornadas, por don Antonio García Gutiérrez.- La frontera de Saboya, traducción de Scribe.- Beneficio del señor Antonio Guzmán» (3-3-1836).

5.- «Teatro del Príncipe. Función extraordinaria a beneficio de la señora Lamadrid» (9-3-1836).

6. - «Teatro del Príncipe. El Trovador, a beneficio de su autor D. Antonio García Gutiérrez» (15-3-1836).

7.- «Teatros. Príncipe.- Primera representación de Catalina Howard, drama traducido de Mr. Alejandro Dumas» (20-3-1836).

8.- «Teatro del Príncipe. Función extraordinaria.- Beneficio de la señora M. Díez» (26-3-1836).

9.- «Al Gave» (3-4-1836).

10.- «Teatro de la Cruz. Primera salida de la señora Juana Pérez.- La reina de quince años.-Las gracias de la vejez (7-4-1836).

11.- «Teatro del Príncipe. Primera representación de Luis XI» (12-4-1836).

12.- «Teatro del Príncipe. Primera representación de la comedia nueva en dos actos titulada Un agente de policia» (30-4-1836).

13.- «Teatro de la Cruz. Primera representación de Un procurador o la intriga honrada, comedia en dos actos, traducida del francés» (13-5-1836).

14.-- «Teatro del Príncipe. Primera representación de Los carlistas en la venta, o el cambio de carteras» (20-5-1836).

15.- «Revista de publicaciones nuevas» $(21-5-1836)$.

16. - «Teatro del Príncipe. Primera representación de El hijo en cuestión, pieza en un acto traducida del francés» (24-5-1836).

17.- «Teatro del Príncipe. Primera representación de Elvira de Albornoz, drama trágico en cinco actos» (27-5-1836).

18.- «Revista de publicaciones» (3-6-1836).

19.- «Teatro del Príncipe. Primera representación de Aben-Humeya, drama histórico en tres actos, de don Francisco Martínez de la Rosa» (10-6-1836).

20.- «Teatro del Príncipe. Primera representación de iEstá loca! Comedia en dos actos traducida del francés (16-6-1836).

21.- «Revista de Publicaciones Nuevas» (20-6-1836)

22.- «Literatura dramática. Don García o el triunfo del amor filial. Tragedia en cinco actos, por don Fernando Corradi» (21-6-1836). 
23.- «Teatro del Príncipe. Primera representación de Antony, drama nuevo en cinco actos, escrito en francés por Alejandro Dumas y traducido al castellano.- Beneficio del actor J. Romea» (24-6-1836).

24.- «Teatro del Príncipe. Primera representación de La redacción de un periódico, comedia en cinco actos» (8-7-1836).

25.-- «Teatro del Príncipe. Literatura dramática. Primera representación de $\mathrm{La}$ favorita. Comedia nueva en dos actos traducida del francés» (26-7-1836), 26.- «Esperanzas literarias» (4-8-1836). 


\section{BIBLIOGRAFÍA}

Calvo Sanz, Roberto, 1974. Don Salvador Bermúdez de Castro y Díez. Su vida y su obra. Contribución a la historia de la literatura romántica, Valladolid, Universidad.

Gamazo Berrueco, Sara, 1989. La «Revista Española» (Madrid, 1832-1836). Introducción, indices y antología, Madrid, ETD Micropublicaciones.

MADRAZO, Pedro de, 1882. «Elogio fúnebre de D. Valentin Carderera. Necrología», Boletín de la Real Academia de la Historia, t. 2, págs. 5-125.

MOnTE y APONTE, Domingo del, 1923. Centón epistolario de Domingo del Monte, Domingo Figarola-CANEDA (ed.), Habana, Academia de la Historia, 7 v.

OCHOA, Eugenio de, 1867. Miscelánea de literatura, viajes y novelas, Madrid, Carlos Bailly-Bailliere.

ROKISKI LÁZARO, Gloria, 1988. Bibliografia de la poesia española del siglo XIX (1801-1850), Madrid, Consejo Superior de Investigaciones Científicas. T. II. Autores y obras anónimas (A-CH).

RomeA, Julián, 1861. Poesias de D. Julián Romea, $2^{\text {a }}$ ed. aum., Sevilla, Imprenta Librería Española y Extranjera.

Ruiz Lagos, Manuel, 1972. Historia de la sociedad económica de amigos del pais de Xerez de la Frontera, Jerez de la Frontera, Publicaciones del Centro de Estudios Históricos Jerezanos. 